\title{
EFFECT OF BATCH INITIAL VELOCITY ON THE GLASS FURNACE EFFICIENCY
}

\author{
Nasim Soleimanian ${ }^{1}$, Mark Jolly ${ }^{2}$, Karl Dearn ${ }^{3}$, Oliver Brinkman ${ }^{4}$, and William Brinkman ${ }^{5}$ \\ ${ }^{1,2}$ Cranfield University, School of Applied Science, Cranfield, Bedfordshire, MK43 0AL, \\ United Kingdom \\ ${ }^{3}$ University of Birmingham, School of Mechanical Engineering, Edgbaston, Birmingham, \\ B15 2TT, United Kingdom \\ 4,5 Glassworks Hounsell limited, Park Lane, Halesowen, West Midlands B63 2QS, \\ United Kingdom.
}

Key Words: CFD, energy efficiency, glass furnace, oscillating batch chargers, batch initial velocity.

\begin{abstract}
Glass manufacturing is a heat intensive process. There is a direct correlation between the batch distribution techniques and the furnace energy consumption, productivity, and quality of the glass manufactured. All four major segments (float, container, fibre, and specialty glasses) would benefit from using an optimised batch distribution technique where possible. Oscillating batch chargers (OBC) have been in use since the early 70s, despite their superior batch shape, coverage, and in turn positive effects on the energy consumption and productivity of the furnace they are almost exclusively used in container glass manufacturing. The OBC's main difference compared with other charging methods is its ability to directly influence the batch initial velocity. This paper reports on results achieved in CFD models (GFM) used to study effect of the machine on the overall energy consumption in the doghouse and the melt space.
\end{abstract}

\section{Introduction}

Glass manufacturing can be divided to four major segments float glass, container glass, fiberglass, and specialty glasses. The financial cost of manufacture, its impact on the environment, lack of standardisation and mounting pressure imposed by the authorities for reduction in emissions means that the industry and its suppliers are utilising CFD modelling in order to tackle these challenges.

The need for high temperature to create and maintain the viscous flow, homogenisation of the glass melt, and maintenance of the process to allow continuous output of glass of the right quality are the contributors to the energy intensive activities that are involved in continuous glass manufacturing. This in turn has resulted in design of large container glass furnaces which have high energy consumption, low specific performance, and high $\mathrm{CO}_{2}$ emissions where the most efficient furnaces in the container glass sector have a specific primary energy consumption of $3.8 \mathrm{GJ} /$ tonne of glass at a level of $50 \%$ cullet in the batch making even very small improvements in efficiency by operation optimisation a value adding activity [1-14].

The theoretical calculated energy required to melt glass is 2 to 3 times less than the energy actually used to melt glass as a result of glass melt passing a zone 5 to 8 times before leaving the tank.[8]. This causes contamination as the result of mixing between the completely molten glass free from bubbles returning to the batch area where there is freshly 
molten non-homogeneous glass, still containing very large numbers of bubbles and un-molten batch. At high temperature some components are dissolved rather than melted. Given that an un-molten batch is a good thermal insulator, it can be transported a long way into the furnace, increasing the need for homogenization which also increases the glass residence time of glass melt. This is why large unbroken strings of batch should be avoided, as should an overall blanket without gaps.

Batch distribution technique is one area where each segment tends to have its preference due to technical and historical reasons $[6,15]$. This paper focuses on oscillating batch chargers (OBC) which have been in use since the early 70s. Despite their proven superior batch shape, coverage, and in turn positive effects on the energy consumption and productivity of the furnace, they are still almost exclusively used in container glass manufacturing [15]. The introduction of an emerging new generation of OBC (with better seal in the doghouse and an improved control system which enables even more control over the batch velocity in the melt space.) has created an opportunity to develop a CFD simulation to improve and identify possible operating optimisation windows.

\section{OBC's Impact on the Glass Melting Process}

\section{Glass Melting process}

Glass melting is a multi-phase process. The furnace uses the intense heat to melt the batch into primary glass, where there is a simultaneous flow of materials in different states, i.e. solid, liquid, and gas. Glass melt being the primary phase, batch particles and gases are the secondary phases dispersed within the continuous phase. The batch (raw material) make up consists of collection of particles of various sizes and cullet pieces.

There are several chemical reactions involved in glass making, where reactive dissolution of sand grains in the primary phase is directly related to the heat flux within the batch pile and sand grain size distribution. The melting kinematics of a batch pile is determined by formation of eutectic melts. When the batch pile is exposed to high temperature (at the edges) its viscosity increases, increasing the viscous flow in the primary phase and begins the endothermic processes in the batch to bring it to the reaction temperature [6-8]. In the melt zone of a glass furnace the heat transferred mainly from radiation (achieved by combustion of fuel and air/oxygen) from the combustion space to the glass-melt tank is used to melt the glass batch and heat the liquid glass already in the furnace [6].

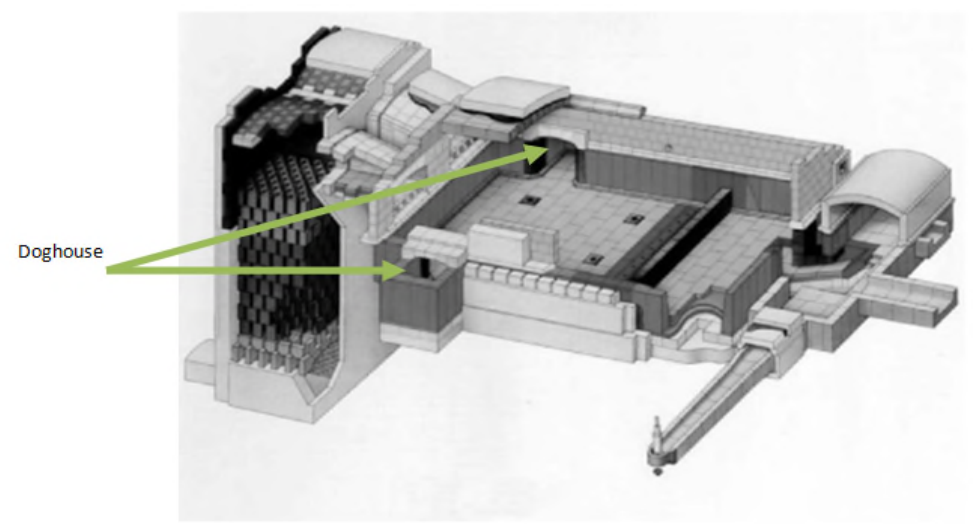

Figure 1. is a end-fired furnace with tow side doghouses. 
The shape and pattern of the batch, its initial velocity, and temperature (depending on the presence of a doghouse (see figure 1) when it enters the melt space is influenced by the type of batch chargers in the process [15].

\section{OBCs and Their Effect on the Energy Consumption in the Melt Space}

OBC's fall under charging systems that can influence the pattern, shape, and initial velocity of the batch. They are positioned on top of the doghouse and they create batch piles which are then pushed in different directions as the equipment swivels on the surface of the glass melt in the doghouse (see figure 2). In such cases the charging flexibility offered by the pusher design currently cannot be bettered, and today this design of charger is the type most commonly used on such furnaces [16]. The calculated energy required to melt glass is 2 to 3 times less than the energy actually used to melt glass [8]. In most cases the glass melt passes a zone 5 to 8 times before leaving the tank. Most of the completely molten glass free from bubbles from the hot spot area returns to the batch area and is mixed with freshly molten nonhomogeneous glass, still containing very large numbers of bubbles and un-molten batch. At high temperature some components are dissolved rather than melted. The un-molten batch is a good thermal insulator making heat transfer within a batch pile difficult. As a result, unmolten batch can be transported a long way into the furnace, increasing the need for homogenization which also increases the glass residence time. This is why large unbroken strings of batch should be avoided, as should an overall blanket without gaps.

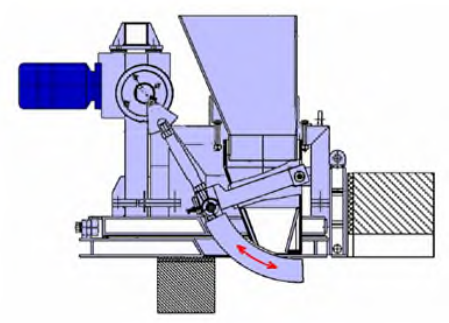

Figure 2. Shows a side profile an $\mathrm{OBC}[16]$.

Soleimanian and Jolly in [15] showed that high space utilisation is essential for reducing energy consumption and increasing the melting performance of a furnace, by optimising and manipulating the ratios between the transversal and longitudinal temperature gradients in the melt space using batch piles. They compare batch patterns produced by different charging methods and show use of OBC maximises the melt space utilisation value for dissolution by improving the spiral critical trajectories close to the glass surface.

Polák, and Němec in [17] state for every given process intensity and melting space there is one maximal value of the space utilisation. Soleimanian and Jolly in [15] show that modeling of the batch pattern is also essential in order to identify maximum space utilisation. Their optimal circulation with spiral flow at the lowest theoretical ratio for the average residence time of glass in the melting space to the fraction of utilised space $(\alpha)$ in their specific 3D melt space was achieved with feeding rate of $0.5 \mathrm{~kg} / \mathrm{s}$, with use of OBC chargers.

$$
\alpha=\frac{\bar{\tau}}{(1-\mathrm{m})}=\frac{\left[\mathrm{H}_{\mathrm{M}}^{0}-\left(\mathrm{H}_{\mathrm{M}}^{\mathrm{T}}+\mathrm{C}^{\mathrm{G}}\left(\mathrm{T}-\mathrm{T}^{\mathrm{e}}\right)\right)\right]}{\frac{\mathrm{AH} \mathrm{H}_{\mathrm{A}}^{\mathrm{L}}}{\rho \mathrm{V}}}
$$

Where $\mathrm{H}_{M}^{0}$ is the specific energy consumption, $\mathrm{H}_{M}^{\mathrm{T}}$ is the theoretical heat needed for glass phase transition, chemical reaction and heating to $\mathrm{T}^{\mathrm{e}}$ (the exit temperature), $\mathrm{C}^{\mathrm{G}}$ is the 
average heat capacity of glass, $\mathrm{T}$ is the melting temperature, $\mathrm{H}_{\mathrm{A}}^{\mathrm{L}}$ is the specific average heat flux above the glass which has a total surface area of $\mathrm{A}, \bar{\tau}$ is the average residence time of glass in the melting space, $\rho$ is the glass density, $\mathrm{V}$ is the volume of the melt space, and $\mathrm{m}$ is the fraction of dead space.

\section{The Batch Initial Velocity Sensitivity Study}

\section{Furnace Model and Batch Composition}

Four different batch velocity combinations were simulated (see table 1). To resemble the OBC batch pattern and its signature random sized batch piles, six inlets with different distances between them, shifted to one side was added to the melt space (see figure 3 ).

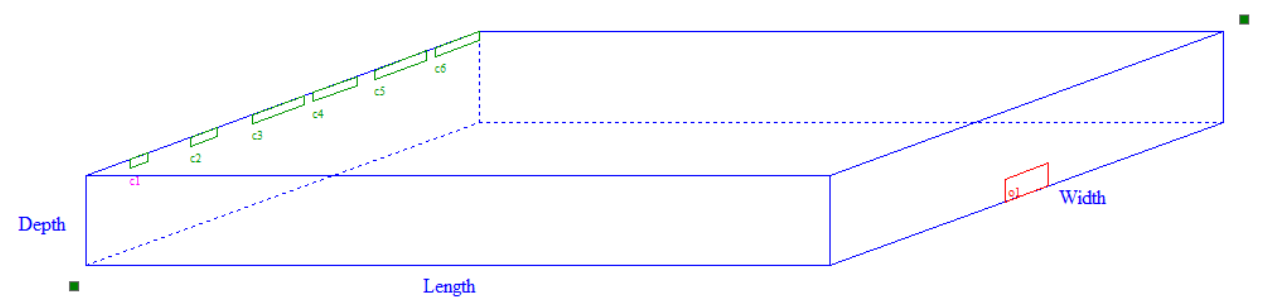

Figure 3. Shows the melt space and the location of 6 batch inlets.

Each inlet dispatches at a different rate (the width of the inlets are corresponding with the rate of dispatch) in order to simulate an oscillating batch charger feeding from the side wall of the furnace.

Table 1. shows the different arrangement batch initial speed for each setup.

\begin{tabular}{|lcccccc|}
\hline & $\mathrm{V}_{\mathrm{C} 1}\left(\mathrm{~ms}^{-1}\right)$ & $\mathrm{V}_{\mathrm{C} 2}\left(\mathrm{~ms}^{-1}\right)$ & $\mathrm{V}_{\mathrm{C} 3}\left(\mathrm{~ms}^{-1}\right)$ & $\mathrm{V}_{\mathrm{C} 4}\left(\mathrm{~ms}^{-1}\right)$ & $\mathrm{V}_{\mathrm{C} 5}\left(\mathrm{~ms}^{-1}\right)$ & $\mathrm{V}_{\mathrm{C} 6}\left(\mathrm{~ms}^{-1}\right)$ \\
Base line & 0.003 & 0.003 & 0.003 & 0.003 & 0.003 & 0.003 \\
Case 1 & 0.005 & 0.004 & 0.003 & 0.003 & 0.003 & 0.003 \\
Case 2 & 0.003 & 0.003 & 0.003 & 0.003 & 0.002 & 0.001 \\
Case 3 & 0.005 & 0.004 & 0.003 & 0.003 & 0.002 & 0.001 \\
\hline
\end{tabular}

The furnace that was modelled was an end-fired, regenerative, container glass furnace. The glass tank is $8 \mathrm{~m}$ long, $4.5 \mathrm{~m}$ wide and $1 \mathrm{~m}$ deep (no bubblers or boosting). The combustion space has an arc shape crown with the minimum and maximum heights of $1.2 \mathrm{~m}$ and $1.45 \mathrm{~m}$ respectively. There are 6 burners in total, and 2 air ports, 1 air port for each set of 3 burners. The direction of flame is changed every $20 \mathrm{~min}$. Soda-lime silicate glass of composition $\mathrm{SiO}_{2}(74 \%)-\mathrm{Na}_{2} \mathrm{O}(16 \%)-\mathrm{CaO}(10 \%)$ (mol) with $50 \%$ cullet was selected as the batch. The batch and glass thermo physical data were from $[10,18]$. All the variables were kept constant excluding batch input rate for each batch pattern. The basic features of the mathematical model and the numerical method employed to compute the flow and temperature in the glass melt and the combustion space are detailed in [7]. The relevant criteria were studied: 1) The $\mathrm{H}_{\mathrm{M}}^{0}$, 2) Glass ex ist temperature, and furnace output rate.

\section{Results}

Changing the batch introduction rate as well as adjusting the initial speed has an optimising effect on the temperature gradient across the melt space. By using batch to enhance the stirring in a melt tank it is possible to achieve high pull and relatively low 
specific energy consumption, where high temperatures may not be the optimum solution (See figures 4,5 , and 6$)[13,15,17]$.

Table 2. The total percentage reduction in $\mathrm{H}_{M}^{0}$ for cases, 1,2 , and 3 .

\begin{tabular}{|ccccc|}
\hline Batch rate in $(\mathrm{kg} / \mathrm{s})$ & $\begin{array}{c}\text { Base line } \\
(\mathrm{MJ} / \mathrm{s})\end{array}$ & $\begin{array}{c}\text { Case 1 } \\
(\%)\end{array}$ & $\begin{array}{c}\text { Case 2 } \\
(\%)\end{array}$ & $\begin{array}{c}\text { Case 3 } \\
(\%)\end{array}$ \\
0.50 & 1.1030 & 0.1238 & -0.2515 & -0.1798 \\
0.75 & 1.6774 & 0.0828 & -0.0598 & 0.0120 \\
1.00 & 2.2159 & 0.0627 & -0.0299 & 0.0136 \\
1.50 & 3.0223 & 0.0182 & -0.0138 & 0.0044 \\
1.75 & 3.7819 & 0.0211 & -0.0090 & -0.0011 \\
2.00 & 4.2634 & 0.0187 & -0.0062 & -0.0003 \\
2.50 & 5.2561 & 0.0000 & -0.0033 & -0.0008 \\
2.75 & 5.8517 & 0.0147 & 0.0114 & -0.0014 \\
3.00 & 6.3356 & 0.0124 & -0.0025 & -0.0017 \\
\hline
\end{tabular}

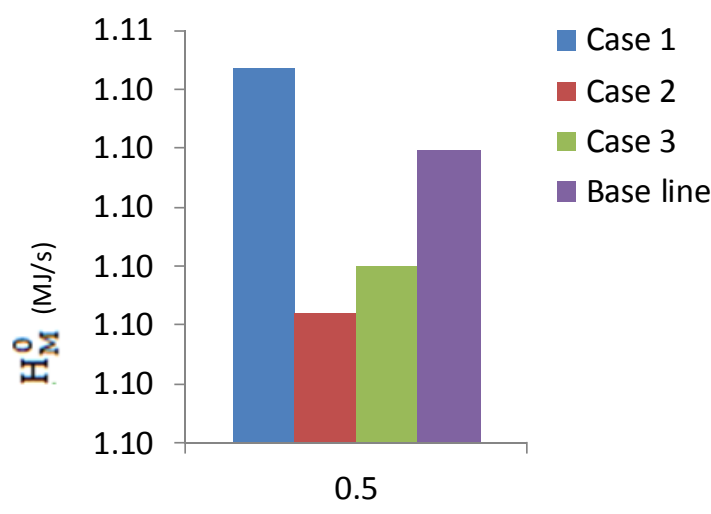

Batch rate in $(\mathrm{kg} / \mathrm{s})$

a)

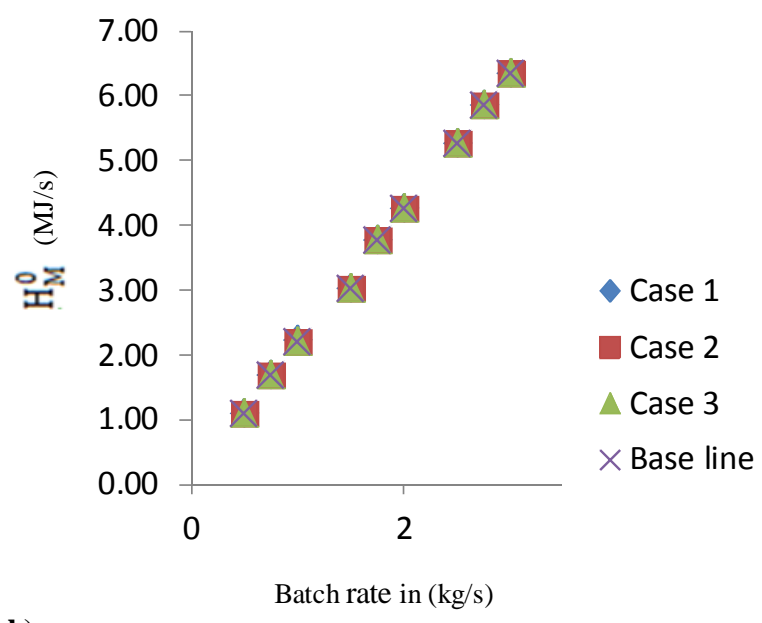

b)

Shows $\mathrm{H}_{\mathrm{M}}^{0}(\mathrm{MJ} / \mathrm{s})$ at total of $0.5 \mathrm{~kg} / \mathrm{s}$ batch input and b) for different batch inlet $(0.5-3 \mathrm{~kg} / \mathrm{s})$.

The results predicted by show (case 1) has the highest $\mathrm{H}_{\mathrm{M}}^{0}$ and $\mathrm{T}^{\mathrm{e}}$ in the group (see figure 4 and 5: $a$ and $b$ ). This is as a result of different velocities along the melt trajectories. The batch pattern produces a broader spectrum of melt residence times in the melt tank, compared to the other cases and temperature differences along the trajectories cause differences of the melting rate. Melting performance is restrict as the result of critical pathways through the melting space increasing the energy demands (see table 2).

As the batch input increases $\mathrm{T}^{\mathrm{e}}$ is kept well between the $1000^{\circ} \mathrm{C}-1200^{\circ} \mathrm{C}$ temperature required for optimal viscosity for cutting the glass to gobs (solid cylinders of glass). By reducing the glass temperature in preparation for the forming process energy loss through water-cooling the feeding channels is also reduced(See figure 5) $[6,15]$. These effects are improved by better managing the gaps, and batch velocity in case 2 . 

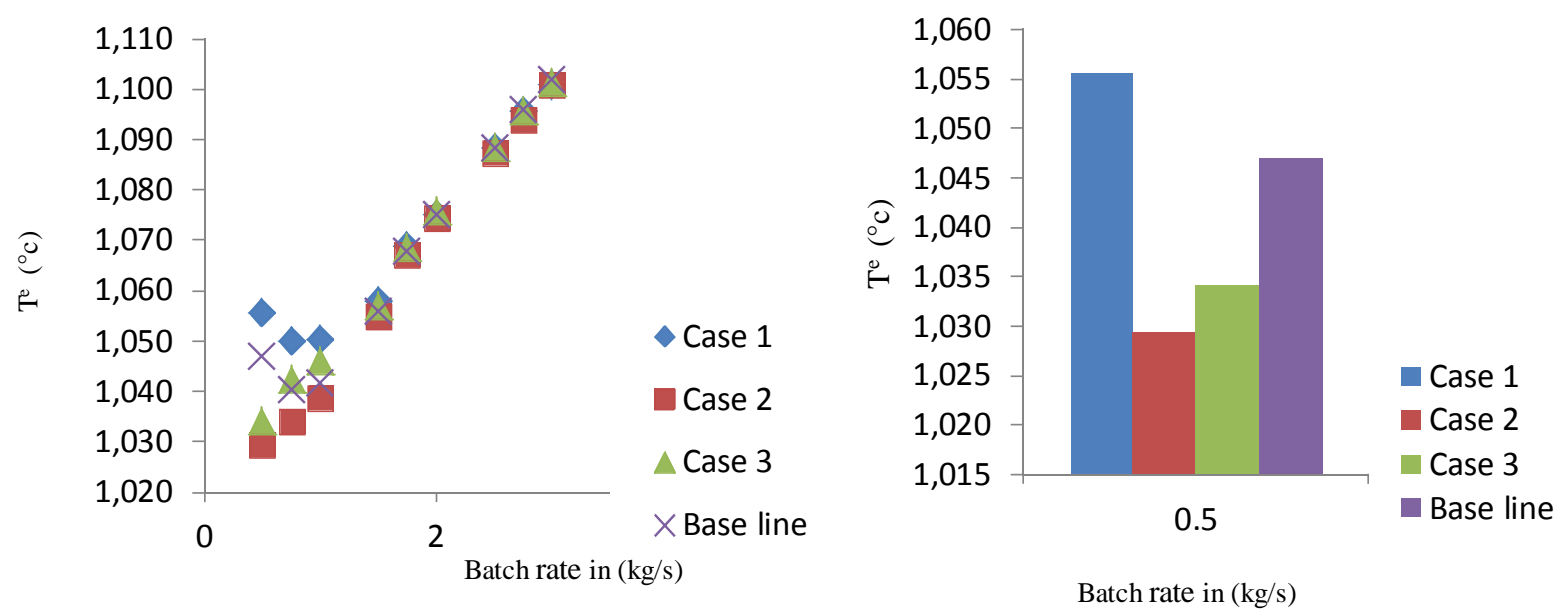

a)

b)

Figure 5. Shows Mean $\mathrm{T}^{\mathrm{e}}\left({ }^{\circ} \mathrm{c}\right)$ a) for different batch inlet $(0.5-3 \mathrm{~kg} / \mathrm{s})$ and b) at total of $0.5 \mathrm{~kg} / \mathrm{s} \mathrm{batch}$ input.

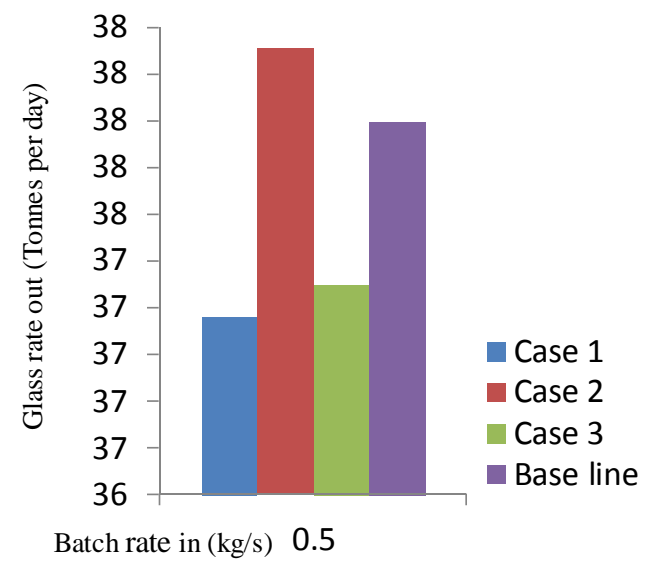

Figure 6. Shows glass rate out (Tonnes per day) for different batch inlet arrangements for $0.5 \mathrm{~kg} / \mathrm{s}$ input.

The result is showing by controlling the patch coverage on the glass melt surface, the introduction of new control system certainly has a positive impact on the overall energy consumption and performance of the furnace.

Further work is needed to establish the total energy savings incurred by use of new generation of OBCs vs in energy losses due to presence of doghouse, in large, high capacity end-fired furnaces, in particular those with high specific melting rates, are particularly dependent on the batch charging technology studied above.

\section{Acknowledgment}

The completion of the above project could not have been accomplished without the support of GLASSWORKS HOUNSELL, and the Funding provided by TSB as part of 8637 KTP project. 


\section{References}

1. Abbassi, A. and K. Khoshmanesh, Numerical simulation and experimental analysis of an industrial glass melting furnace. Applied Thermal Engineering, 2008. 28(5-6): p. 450-459.

2. Beerkens, R., Analysis of elementary process steps in industrial glass melting tanks-some ideas on innovations in industrial Glass melting Ceramics - Silikáty 2008. 52( 4): p. 206-217

3. Beerkens, R.G.C. and J. van der Schaaf, Gas Release and Foam Formation During Melting and Fining of Glass. Journal of the American Ceramic Society, 2006. 89(1): p. 24-35.

4. Beerkens, R.G.C. and J. van Limpt, Energy Efficiency Benchmarking of Glass Furnaces, in 62nd Conference on Glass Problems: Ceramic Engineering and Science Proceedings2008, John Wiley \& Sons, Inc. p. 93-105.

5. Boyd, G.A. and J.X. Pang, Estimating the linkage between energy efficiency and productivity. Energy Policy, 2000. 28(5): p. 289-296.

6. C. Philip Ross, G.L.T., Glass Melting Technology: A Technical and Economic Assessment M. Rasmussen, Editor 2004, U.S. Department of Energy. p. 292.

7. Chang, S.L., C.Q. Zhou, and B. Golchert, Eulerian approach for multiphase flow simulation in a glass melter. Applied Thermal Engineering, 2005. 25(17-18): p. 3083-3103.

8. Charles H. Drummond, I., 72nd Conference on Glass Problems: Ceramic Engineering and Science Proceedings2012: Wiley.

9. Choudhary, M.K., Recent Advances in Mathematical Modeling of Flow and Heat Transfer Phenomena in Glass Furnaces. Journal of the American Ceramic Society, 2002. 85(5): p. 1030-1036.

10. Fluegel, A., Glass viscosity calculation based on a global statistical modelling approach. Glass Technology - European Journal of Glass Science and Technology Part A, 2007. 48(1): p. 1330.

11. Jiang, S., Advances in Glass and Optical Materials: Proceedings of the 107th Annual Meeting of The American Ceramic Society, Baltimore, Maryland, USA 2005, Ceramic Transactions2012: Wiley.

12. Levitin, L., et al., Raw materials with prescribed properties - additional resources for increasing glass-furnace efficiency and float-glass quality. Glass and Ceramics, 2012. 69(1): p. 3-8.

13. mec, L., Jebav, and Marcela, Analysis of the performance of glass melting processes as a basis for advanced glass production. Glass Technology - European Journal of Glass Science and Technology Part A, 2006. 47(3): p. 68-77.

14. Paramonova, O., et al., Study of glass batch components segregation. Glass and Ceramics, 2012. 68(9): p. 319-322.

15. Soleimanian, N. and M. Jolly, Effect of Batch Charging Equipment on Glass Furnace Efficiency, in Energy Technology 20132013, John Wiley \& Sons, Inc. p. 77-84.

16. Sims, R. Batch charging technologies - a review. [Online] 2007 [cited 2007.

17. Polák, M. and L. Němec, Glass melting and its innovation potentials: The combination of transversal and longitudinal circulations and its influence on space utilisation. Journal of Non-Crystalline Solids, 2011. 357(16-17): p. 3108-3116.

18. Seward, T.P. and T. Vascott, High temperature glass melt property database for process modeling2005: American Ceramic Society. 
2014-01-10

\section{Effect of batch initial velocity on the glass furnace efficiency}

Soleimanian, Nasim

Wiley

Soleimanian, N. et al. (2014) Effect of batch initial velocity on the glass furnace efficiency, Energy Technology 2014: Carbon Dioxide Management and Other Technologies, 16-20

February 2014, San Diego, CA, USA

http://dx.doi.org/10.1002/9781118888735.ch26

Downloaded from Cranfield Library Services E-Repository 